\title{
Выбор оптимального средства для местного лечения фарингита у детей
}

\section{Contacts:}

Soldatskii Yurii L'vovich, PhD, professor of the Department of Diseases of Ear, Throat and Nose of I.M. Sechenov 1st MSMU Address: 1/3, Rubtsovsko-Dvortsovaya Street, Moscow, RF, 107014, Tel.: (499) 268-83-81, e-mail: ysoldatsky@mail333.com Article received: 12.03 .2012 , Accepted for publication: 12.04 .2012

Рассматриваются этиология и патогенез острого фарингита у детей. Обосновывается оптимизация лечения заболеваний, сопровождающихся болью в горле, с применением топических препаратов, таких как Стрепсилс, обладающего обезболивающим и антибактериальным действием.

Ключевые слова: боль в горле у детей, острая вирусная инфекция, острый фарингит, топическая симптоматическая терапия.

Боль в горле - одна из наиболее частых причин обращения к терапевтам, педиатрам и оториноларингологам. До 80\% острых и обострений хронических респираторных заболеваний сопровождаются этим симптомом. Более того, острые фарингиты составляют 6\% всех визитов к педиатру [1]. При этом боль в горле может являться доминирующей проблемой, неизбежно отражаясь на качестве жизни пациента [2]. В большинстве случаев острые фарингиты вызваны вирусами, поражающими слизистую оболочку верхних дыхательных путей, в первую очередь рино-, корона- и аденовирусами. Основным бактериальным агентом, вызывающим острый фарингит, является b-гемолитический стрептококк группы А, который обнаруживают в 15\% случаев [3, 4].

Дети наиболее подвержены респираторным заболеваниям - они вдвое чаще взрослых страдают от боли в горле [5]. Высокая частота заболеваемости связана с длительным пребыванием ребенка в организованном коллективе - детском саду или школе, т.е. в условиях, где важную роль играет теснота контакта. Немалое значение имеет ухудшение экологической обстановки, особенно в больших городах. Ослабление организма, переохлаждение, наличие хронических очагов инфекции (например, кариеса) - факторы, которые также способствуют возникновению респираторных заболеваний [6].

Оптимизация лечения заболеваний, сопровождающихся болью в горле у детей, - одна из основных задач врача. В настоящее время на рынке представлено немало схем лечения боли в горле у детей, и перед врачом встает вопрос выбора оптимального препарата.

Рациональная антибактериальная терапия предусматривает назначение препарата с целью максимально быстрого клинического и бактериологического выздоровления. К препарату, который назначается эмпирически, предъявляются определенные требования: 1) спектр действия препарата должен соответствовать вероятному возбудителю инфекции; 2) препарат должен преодолевать возможно имеющиеся у микроорганизма механизмы резистентности; 3) создавать максимальную концентрацию в очаге инфекции. Назначение системных антибиотиков при остром фарингите показано только при инфекции, вызванной b-гемолитическим стрептококком группы А. Результаты многочисленных исследований, основанных на принципах доказательной медицины, свидетельствуют о необходимости избегать применения антибиотиков при терапии острых

J.L. Soldatskiy, E.K. Onufrieva, S.F. Gasparyan, N.V. Tcshepin, A.M. Steklov

I.M. Sechenov First Moscow State Medical University

\section{Choosing of the optimal local medicine for the treatment of pharyngitis in children}

The cause of the sore throat in children is acute pharyngitis. The etiology and pathogenesis of this disease is discussed in the article. The authors explain the optimization of treatment with such topic drugs with anaesthetic and antibacterial actions as Strepsils in children with diseases associated with sore throat.

Key words: sore throat in children, acute viral infection, acute pharyngitis, topic symptomatic therapy. 
фарингитов нестрептококковой этиологии [7, 8]. Тем не менее, несмотря на некоторое снижение частоты применения антибиотиков по поводу острого фарингита в последние годы, их продолжают назначать (45-60\% наблюдений) $[9,10]$. Более того, в большинстве случаев системные антибиотики при фарингите, в т. ч. и вирусной этиологии, используют именно для купирования боли в горле, а не с целью эрадикации возбудителя [11]. Естественно, необоснованная антибактериальная терапия способствует развитию резистентности к антибиотикам, возникновению нежелательных реакций на лекарство, а также удорожает лечение.

При неосложненном течении заболевания обычно показана местная симптоматическая терапия. Традиционно для лечения острых фарингитов используют полоскания щелочными и дезинфицирующими растворами, обильное теплое питье, обработку задней стенки глотки раствором Люголя и т.д. При фолликулярном фарингите улучшение симптоматики происходит быстрее при применении местной антибактериальной терапии, позволяющей адекватно воздействовать на слизистую оболочку ротоглотки [12]. В связи с этим для терапии неосложненных острых и обострений хронических фарингитов целесообразно использование топических препаратов, обладающих противовоспалительным, анальгезирующим, иммунокорригирующим действием. При этом препарат должен обладать широким спектром антибактериальной активности; низкой скоростью абсорбции; отсутствием токсического и раздражающего действия на слизистую оболочку; низкой аллергенностью. Дополнительными условиями, особенно актуальными в педиатрической практике, должны быть удобство применения и отсутствие неприятных вкусовых ощущений.

На фармацевтическом рынке представлен широкий выбор средств для местного лечения воспалительных заболеваний глотки, которые в зависимости от лекарственной формы можно разделить на 3 группы: растворы для полоскания, аэрозоли, таблетки для рассасывания. Существуют работы, свидетельствующие о преимуществах использования таблеток для рассасывания над лекарственным аэрозолем и раствором для полоскания [13]. По данным гамма-сцинтиграфии, лекарственное вещество, помеченное радиоизотопом, дольше сохраняется на слизистой оболочке глотки и полости рта при использовании таблетки для рассасывания, чем при применении аэрозоля и особенно раствора для полоскания. Кроме того, площадь эффективного воздействия препарата и его концентрация достигают максимальных значений именно при использовании таблеток для рассасывания [13].

К наиболее популярным у населения препаратам безрецептурного отпуска для местной терапии инфекционновоспалительных заболеваний полости рта и глотки относятся таблетки для рассасывания и аэрозоли, содержащие в качестве активного компонента гексетидин.

Согласно исследованиям, таблетки для рассасывания являются оптимальной лекарственной формой средства от боли в горле $[14,15]$ - увеличение слюноотделения при рассасывании таблетки [14] обеспечивает смягчающий и успокаивающий эффект в очаге воспаления [16] и способствует смыванию патогенных микроорганизмов с поверхности слизистой оболочки [14]. Со слюной выделяется лизоцим - природный антисептик, обладающий, помимо активности в отношении грамположительных, грамотрицательных бактерий, грибов и вирусов, иммуномодулирующим действием [17]. Кроме того, растворение таблетки в ротовой полости происходит постепенно, что обеспечивает длительное воздействие на очаг воспаления, в том числе на труднодоступные участки [18], а доставка активного компонента непосредственно в очаг воспаления обеспечивает быстрый эффект [19].

Таблетки для рассасывания Стрепсилс (Рекитт Бенкизер Хелскэр, Великобритания) содержат два действующих вещества - амилметакрезол (600 мкг) и 2,4-дихлорбензиловый спирт (1,2 мг). Препарат обладает антисептическим (антибактериальным и антимикотическим) действием. Активен в отношении широкого спектра грамположительных и грамотрицательных микроорганизмов, в т.ч. в отношении большинства штаммов стафилококка (Staphylococcus epidermidis, Streptococcus pyogenes, Staphylococcus aureus, Streptococcus salivarius), стрептококков групп A, C и D, Diplococcus pneumoniae, Pseudomonas aeruginosa, Klebsiella aerogenes, Haemophilus influenzae, Proteus spp., Aerobacter aerogenes, Aerobacter cloacae и др., а также дрожжеподобных грибов Candida albicans. Кроме того, существуют данные, демонстрирующие противовирусную активность этого препарата [20].

Стрепсилс уменьшает ощущение инородного тела, раздражение в глотке и полости рта; устраняет боль, першение, чувство саднения в глотке. Обезболивающее действие препарата проявляется примерно через 5 мин [21] и продолжается до 2 ч [21, 22]. Из-за низкого всасывания препарата отсутствует системный эффект - токсическая доза для человека составляет около 70 тыс. доз. Предложено 6 различных вкусовых вариантов таблеток для рассасывания.

В 1 мл аэрозоля для местного применения (ATX группа "А01АВ12 Гексетидин») содержится 2 мг гексетидина, обладающего антисептическим, анальгезирующим, кровоостанавливающим действием. Гексетидин активен в отношении грамположительных и грамотрицательных микроорганизмов, в т.ч. стафилококков, стрептококков, $P$. aeruginosa, Proteus spp. и грибов рода Candida. Гексетидин также оказывает обволакивающее действие на слизистую оболочку. Действие препарата продолжается 10-12 ч. В целом, показания к применению и терапевтическая активность обоих препаратов аналогичны.

Цель настоящего исследования: сравнить клиническую эффективность местной антибактериальной терапии острого и обострения хронического фарингита у детей при помощи таблеток для рассасывания и лекарственного аэрозоля, содержащего гексетидин.

\section{МАТЕРИАЛЫ И МЕТОДЫ}

В исследование были включены 50 пациентов в возрасте от 5 лет 7 мес до 16 лет, обратившиеся в консультативно-диагностический центр Детской городской клинической больницы св. Владимира. Рандомизация проводилась в порядке обращения: "нечетные" больные составили I группу, "четные" II группу. Помимо традиционной и симптоматической терапии, пациенты I группы получали дополнительно по 1 таблетке для рассасывания каждые 2-3 ч (не более 5-6 табл. в течение 24 4); пациенты II группы обрабатывали заднюю стенку глотки аэрозолем, содержащим в качестве активного компонента гексетидин, 2 раза в сут (утром и вечером) после приема пищи (исследуемые препараты назначались согласно инструкциям по применению) 


\section{Критерии включения в исследование:}

- жалобы на боль в горле;

- наличие симптомов острого или обострения хронического фарингита нестрептококковой этиологии;

- наличие симптомов заболевания до 3 сут к моменту обращения;

- отсутствие на момент обращения показаний к назначению системных антибиотиков;

- отсутствие на момент обращения показаний к госпитализации;

- возраст детей старше 5 лет;

- согласие родителей ребенка на участие в исследовании.

\section{Критерии исключения из исследования:}

- развитие осложнений заболевания (острой респираторной инфекции), потребовавших назначения системных антибиотиков;

- прекращение приема препаратов;

- неявка на контрольный осмотр.

Продолжительность лечения составила 7 сут. Оценку выраженности болевого синдрома проводили сами пациенты (или их родители) при помощи визуально-аналоговой шкалы, при этом за 0 принималось отсутствие болевых ощущений, за 10 - их максимальная выраженность. Во время визитов больного (при первичном посещении, на 3 и 7-е сут) по 4-балльной шкале врач оценивал местные симптомы воспаления в ротоглотке (отек мягких тканей задней и боковых стенок глотки, гиперемия слизистой оболочки, выраженность лимфоидных гранул задней стенки глотки и боковых столбов). Переносимость препарата больные оценивали самостоятельно по 4-балльной визуально-аналоговой шкале на 7-е сут лечения.

В связи с развившимися осложнениями респираторной инфекции, потребовавшими назначения системных антибиотиков, из исследования были исключены 4 пациента (3 детей с острым синуситом и 1 ребенок с острым средним отитом); еще 5 больных не явились на контрольный осмотр. Таким образом, I группу составил 21 пациент (12 мальчиков и 9 девочек; средний возраст 10,3 \pm 2,6 лет); II группу - 20 больных (11 мальчиков и 9 девочек; средний возраст 10,0 $\pm 2,3$ лет). В течение первых суток заболевания к врачу обратились 33,3\% пациентов I группы и 35\% - II группы; на вторые сутки - 42,9 и 40\%; на третьи сутки - 23,8 и 25\%, соответ- ственно. Обе группы были сопоставимы по возрасту, полу и срокам обращения в клинику $(p>0,05)$.

Статистическая обработка результатов исследования проведена на персональном компьютере с помощью пакетов программ STATGRAPHICS Plus 3.0, Microsoft Excel 97 с использованием параметрических и непараметрических критериев. Доверительные интервалы для средних величин вычислялись с заданным уровнем достоверности 9,95. Различие средних величин считалось достоверным при уровне значимости $p<0,05$, соответствующим достоверной вероятности 0,95 и более.

\section{РЕЗУЛЬТАТЫ ИССЛЕДОВАНИЯ}

На момент обращения к врачу выраженность болевой реакции (рис. 1) у детей обеих групп была сопоставима ( $p>0,05)$. На 3-и сут лечения все пациенты отмечали значительное уменьшение болевого синдрома, однако у больных I группы его выраженность была достоверно меньше ( $p=0,046)$. К 7-м сут терапии достоверной разницы между группами не отмечалось: легкая болезненность или ощущение дискомфорта в горле сохранялось лишь у 14,3\% пациентов I группы и у $20 \%$ - II группы ( $p=0,357)$. Начиная с первого дня лечения, пациенты отмечали выраженное обезболивающее действие таблеток для рассасывания длительностью до одного часа. И хотя длительность анальгезирующего эффекта аэрозоля была несколько выше, возможность более частого применения таблеток позволяла эффективнее купировать болевой синдром.

Фарингоскопические симптомы заболевания при обращении (рис. 2) в обеих группах были сопоставимы $(p=0,357)$. На фоне терапии к 3-м сут у всех больных отмечено значительное улучшение фарингоскопической картины, однако аналогично с купированием болевого синдрома положительная динамика была статистически значимо лучше у детей I группы ( $p=0,043)$. К окончанию лечения достоверной разницы в эффективности терапии между обеими группами не отмечено: фарингоскопическая картина нормализовалась у $81 \%$ детей I группы и 75\% - II группы ( $p=0,328)$.

По окончании лечения больные (или их родители) оценивали переносимость препаратов и удобство их применения (рис. 3). В целом, несмотря на отсутствие статистически достоверной разницы ( $p=0,095)$, паци-
Рис. 1. Выраженность болевой реакции и/или дискомфорта в горле

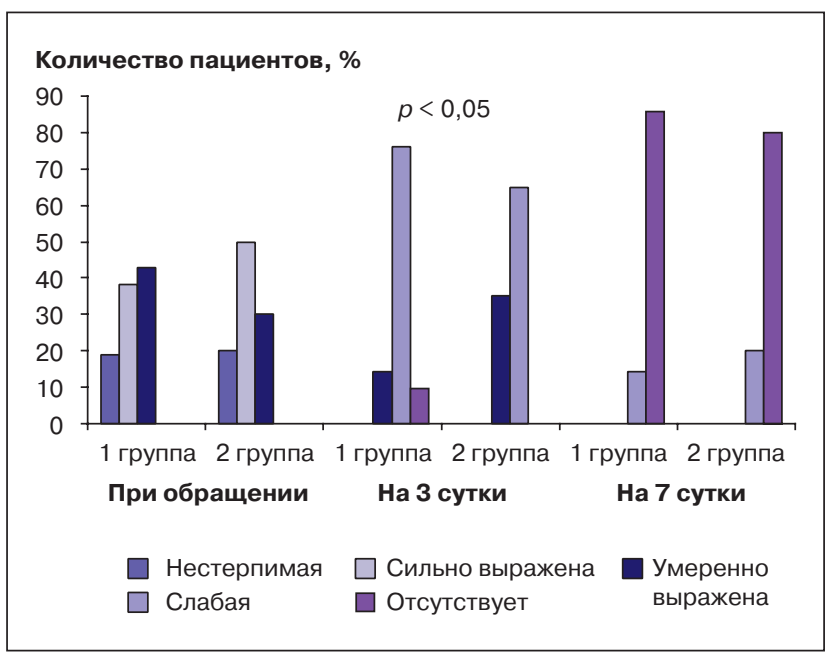

Рис. 2. Динамика фарингоскопической картины

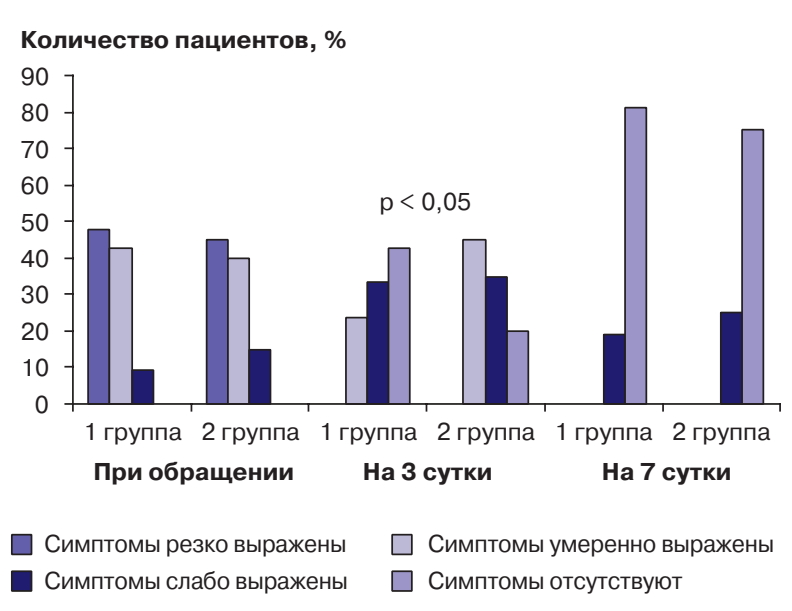


енты I группы оценили эффект терапии более высоко. Немаловажным преимуществом препарата является возможность выбрать "таблетку по вкусу", стимулируя ребенка участвовать в процессе лечения. На российском рынке представлено 5 вариантов таблеток для рассасывания, разрешенных для применения у детей, начиная с 5-летнего возраста: "оригинальные"; "медово-лимонные"; "лимонные без сахара"; "с ментолом и эвкалиптом"; "апельсиновые с витамином C", и один вариант таблеток для рассасывания, разрешенных к применению у детей с 12-летнего возраста. Таблетки для рассасывания со вкусом лимона, содержащие натрия сахаринат в качестве заменителя сахара, оптимально применять в педиатрической практике с целью профилактики кариеса.

Побочных эффектов или аллергических реакций в ходе исследования не было выявлено ни в одном случае.

\section{ЗАКЛЮЧЕНИЕ}

Местное применение антибактериальных препаратов является эффективным и достаточным у больных острым фарингитом, вызванным отличной от b-гемолитического стрептококка группы А патогенной флорой. Полученные данные свидетельствуют о более высокой эффективности таблеток для рассасывания по сравнению с лекарственным аэрозолем в купировании симптомов острого и обострения хронического фарингита, в первую очередь
Рис. 3. Оценка пациентами переносимости терапии

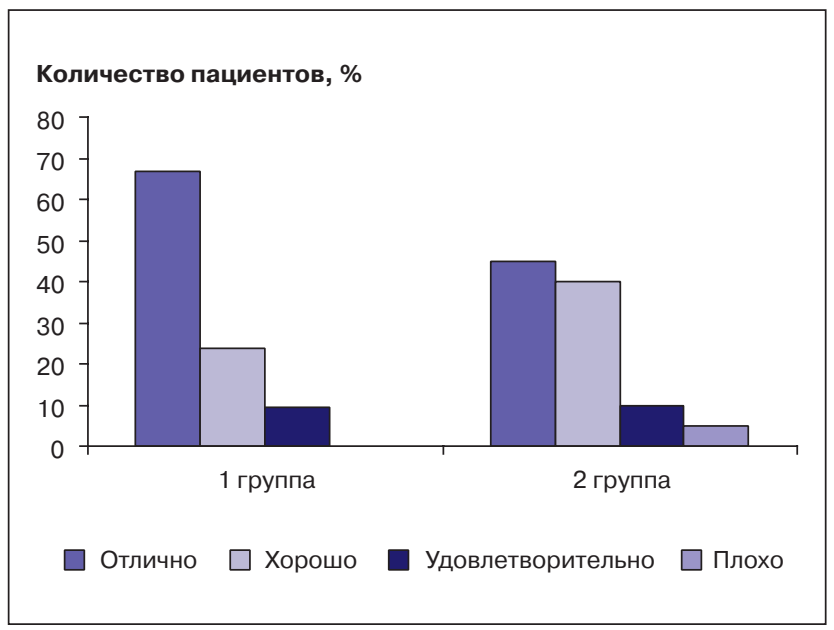

болевого синдрома, тем самым улучшая качество жизни пациента. Стрепсилс - оптимальное лекарственное средство, характеризующееся высоким уровнем безопасности и эффективности, для топической симптоматической терапии острых хронических фарингитов и его обострений в педиатрической практике.

\section{REFERENCES}

1. Nash D. R., Harman J., Wald E.R. et al. Antibiotic prescribing by primary care physicians for children with upper respiratory tract infections. Arch. Pediatr. Adolesc. Med. 2002; 156 (11): 1114-1119. 2. Babiyak V.I., Govorukhin M.I., Mitrofanov V.V. Ros. otorinolaringologiya - Rissian Otolaryngology. 2004; 1 (8): 3-6.

3. Lopatin A.S. RPZh - Russian Journal of Psychiatry. 2001; 9 (16-17): 765-769.

4. Bisno A. L., Gerber M.A., Gwaltney J. M. et al. Practice guideline for the diagnosis and management of group A streptococcal pharyngitis. Clin. Infect. Dis. 2002; 35 (2): 113-125.

5. Lindbaek M. Clinical course of suspected viral sore throat in young adults: Cohort study. Scandinavian J. of Primary Health Care. 2006; 24: 93-97.

6. Balyasinskaya G. L. Consilium Provisorum - Consilium Provisorum. 2004; 4 (1).

7. Snow V., Mottur-Pilson C., Cooper R.J., Hoffman J.R. Principles of appropriate antibiotic use for acute pharyngitis in adults. Ann. Intern. Med. 2001; 134 (6): 506-508.

8. Park S. Y., Gerber M. A., Tanz R. R. et al. Clinicans' management of children and adolescent with acute pharyngitis. Pediatrics. 2006; 117 (6): 1871-1878.

9. Linder J.A., Bates D.W., Lee G. M., Finkelstein J.A. Antibiotic treatment of children with sore throat. JAMA. 2005; 294 (18): 2315-2322. 10. Ashworth M., Latinovic R., Charlton J. et al. Why has antibiotic prescribing for respiratory illness declined in primary care? A longitudinal study using the General Practice Research Database. J. Public. Health. 2005; 26 (3): 268-274.

11. van Driel M. L., De Sutter A., Deveugele M. et al. Are sore throat patients who hope for antibiotics actually asking for pain relief? Ann. Fam. Med. 2006; 4 (6): 494-499.

12. Ratsional'naya antimikrobnaya terapiya. Rukovodstvo dlya praktikuyushchikh vrachei. Pod red. V. P. Yakovleva, S. V. Yakovleva [Sensible Antimicrobial Therapy. Guideline for Practicing Doctors. Edited by V.P. Yakovlev, S. V. Yakovlev]. Moscow, Litterra, 2003. $1008 \mathrm{p}$.

13. Church A., Evans P., Pickford M. et al. Scintigraphy: an appropriate methodology to assess the effectiveness of medication formats in providing local delivery to the mouth and throat. Annual Scientific Meeting of the British Pain Society. Glasgow.

14. Wade A.G., Marshall L.E., Simpson M. et al. Bioavailability and efficacy of active lozenges in the relief of sore throat pain. Poster presented at the Annual Scientific Meetings of The British Pain Society, 24-27 April 2007. Glasgow, UK.

15. Oxford J.S. and Leuwer M. Acute sore throat revisited: clinical and experimental evidence for the efficacy of over-the-counter AMC/DCBA throat lozenges. Int. J. Clin. Pract. May 2011; 65 (5): 524-530.

16. Marshall S. Giving advice on sore throats. Pharm. J. 2008; 280: $127-130$.

17. Mandel I.D. The functions of saliva. J. Dent. Res. 1987; 66 Spec No: 623-627.

18. Limb M., Connor A., Pickford M. et al. Scintigraphy can be used to compare efficacy of sore throat formulations. Int. J. Clin. Pract. 2009; 63: 606-612.

19. Mal'tseva G.S. Consilium Medicum - Consilium Medicum. 14 (3): 53-55.

20. RSV, SARS-assoziiertes Coronavirus, Influenza-A-Virus. A throat lozenge containing amylmetacresol and dichlorobenzyl alcohol has a direct virucidal effect on respiratory syncytial virus, influenza A and SARS-CoV. Antivir. Chem. \& Chemother. 2005; 16: $129-134$.

21. McNally D. et al. Rapid relief of acute sore throat with AMC/DCBA throat lozenges: randomised controlled trial. Int. J. Clin. Pract. 2010; 64: 194-207.

22. Wade A.G. A randomized, double-blind parallel-group, placebo-controlled, multiple-dose study of the efficacy of Strepsils lozenges in the relief of acute sore throat. In: Oxford JS. ed. Developments in acute sore throat relief efficacy and sensorial benefits of medicated lozenges. Royal society of Medicine Press Ltd. 2008: 22-32. 